\title{
TO DEVELOP AN INTELLIGENT INTEGRATED SUPPORT SYSTEM FOR ENGINEERING PROJECT (E-PMS): DECRIS AND DLDS ANALYSIS
}

\author{
Jae Min. Cho ${ }^{1}$, Sin Ae. Jang ${ }^{2}$, Eul Bum. Lee ${ }^{3}$ and Ju Hoon. Lee ${ }^{4}$
}

\begin{abstract}
In order to manage engineering projects systematically and efficiently, the process of each project execution should be organically linked. The authors developed E-PMS (Engineering-Project Management System) for the linkage of processes. A tool called DECRIS (Detailed Engineering Completion Rating Index System) was developed to measure the completeness at the detailed design stage and to identify the starting point of construction (Steel Cutting). This helps the EPC contractor carry out the project by analysing the impact on schedules and costs during the engineering phase. Next is the DLDs Analysis. This study analysed the relationship between the results of the catch-up of the construction period and the delay liquidated damages (DLDs) based on limited resources and develops a model that can support the decision on whether to perform catch-up. The validity criterion of the model is that the results of the simulation of schedule shortening do not exceed the full DLDs incurred due to no catch-up plan. The result of the schedule catch-up simulation is the cost, which is the sum of the additional budget for a catch-up and the remaining DLDs. The reason for the validation criteria mentioned above is that the costs incurred for acceleration when excessive construction was performed to comply with the construction period can exceed the full DLDs.
\end{abstract}

Keywords: Project Management, EPC (Engineering, Procurement, Construction), Delay Liquidated Damages, Intelligent Project Management Information System, Construction Project Management System, Risk Management, Intelligent DecisionMaking System.

\section{INTRODUCTION}

As the size and complexity of projects increased in the global plant market, management risks such as cost increase of project and delay in construction period increased from project order to completion. As a result, the improvement of management capability through decision support in each project phase is emerging as an important topic. Many advanced construction companies are building and using PMIS (Project Management Information System) for engineering-procurement-construction (EPC) project management to enhance the competitiveness and profitability of their engineering businesses. However, currently used PMIS is insufficient in extracting, storing, and standardizing raw data supporting key elements of project management such as process and cost. It is usually only a simple confirmation of performance compared to the

1 Researcher, Graduate Institute of Ferrous Technology (GIFT), Pohang University of Science and Technology (POSTECH), Pohang, Korea, jaemincho@postech.ac.kr

Researcher, POSTECH, Pohang, Korea, sinaejang@postech.ac.kr

Professor(Corresponding Author), POSTECH, Pohang, Korea, dreblee@postech.ac.kr

Researcher, Korea Evaluation Institute of Industrial Technology (KEIT), Daegu, Korea, poweron@keit.re.kr 
progress rate calculation plan. Pre-emptive and proactive risk management capabilities are low. To manage engineering projects systematically and efficiently, processes by stages of project execution should be organically linked. In addition, to maximize the management efficiency of each process, raw data extraction, storage, and standardization techniques for risk management such as process and cost are required. Based on this data, an Engineering Project Life Cycle Management System should be established, and it is essential to develop a system that supports decision-making by providing decision criteria and data for each stage of execution. The study consists of $<1>$ intelligent engineering integrated management frame-work, $<2>$ element technology for integrated project management, $<3>$ decision-making technology supporting integrated project management, <4> business owner LC response PMC technology, and, <5> integrated management system construction and verification. Among them, the authors developed a part of $<3>$ decision-making technology that supports project management. The purpose of this paper is to introduce the Engineering Project Management System (E-PMS) developed through this research project briefly, especially two core modules related to E-PMS's decision-making technology and these are namely DECRIS and DLDs Analysis. The research was supported by the Ministry of Trade, Industry and Energy for 33 months and $\mathrm{R} \& \mathrm{D}$ was conducted to strengthen the competitiveness of the EPC project. This study was conducted by a consortium of three universities and four industries. USD 5.0M was supported by the Ministry of Trade, Industry and Energy.

\section{LITERATURE REVIEW}

As projects and their environments become more complex, there is a growing need for smarter systems that support decision-making and systematically manage project information as uncertainty, time and cost pressures. Accordingly, various research for the development of more intelligent PMIS have been conducted. [1] F.J.Jungen (1995) studied the framework for building an intelligent interactive project management support system. It presents a general framework for developing complex systems for tasks such as project management, dynamic scheduling, and design. [2] Ali Jaafari (1998) presents a new generation of PMIS called the Smart Project Management Information System (SPMIS), and the framework for SPMIS. [3] Paolo Donzelli (2006) studied the application of decision support systems for software project management. The hybrid modeling approach allows project managers to quickly generate process models that can provide accurate predictions, design desired project trajectories, and verify process changes. [4] Xiaoqing (Frank) Liu (2006) conducted a study of systems that help to assess the risks associated with three major problems of software projects: over budget, behind schedule, and poor quality. The system is based on fuzzy logic using an integrated set of software metrics. [5] Peter Smith (2016) studied the use of BIM to manage project costs. [6] Nathalie Labonnot (2017) demonstrated a design methodology that provides several frameworks for decision support systems related to the construction industry for more sustainable and intelligent construction. [7] Chang-Won Kim (2018) proposed an earlywarning performance monitoring system (EPMS) to objectively measure and monitor project performance in order to detect inherent poor performance problems early. EPMS is built on project progress data and consists of a project information database, with an optimized theoretical model used as a performance metric, and an index for performance monitoring and prediction. As mentioned above, various studies have been conducted to improve the PMIS. However, in the above-mentioned previous studies, research on 
To develop an intelligent integrated support system for engineering project (E-PMS): DECRIS and DLDs analysis

decision making models from the perspective of project management was absent during the whole phase of the EPC project field.

\section{E-PMS(ENgineERING Project Management System)}

E-PMS is a case-based Engineering Project Management System that supports optimal decision-making of engineering projects for each phase of the project. E-PMS can quickly and accurately identify the status of a project to be successfully completed in a timely manner, facilitate communication by sharing information among team members, unify data management, avoid duplicate work, and identify potential problems. It is a system for maximizing work efficiency through securing action time, standardizing work, and systemizing. E-PMS menu is divided into 'decision sup-port' and 'project management', and 'decision support' has two special modules, one is DECRIS, and the other is DLDs Analysis.

Table 1: E-PMS function overview

\begin{tabular}{|c|c|c|}
\hline Category & Module & Description \\
\hline \multirow[t]{2}{*}{$\begin{array}{l}\text { Decision } \\
\text { Support }\end{array}$} & Navigator & $\begin{array}{l}\text { Project cost and construction period } \\
\text { prediction and adequacy analysis by using } \\
\text { DECRIS, ES-Chart, DLDs }\end{array}$ \\
\hline & Dashboard & Project Status/Forecast/Risk \& Forecast \\
\hline \multirow{5}{*}{$\begin{array}{l}\text { Project } \\
\text { Management }\end{array}$} & Project & $\begin{array}{l}\text { Project Information Inquiry, Revision } \\
\text { Management, Report Cycle Management, Site } \\
\text { Location Inquiry Project Organization } \\
\text { Information Inquiry, Project Image Inquiry, } \\
\text { Supplier Inquiry Notice Board, Free Board, } \\
\text { Individual / Project Schedule Management, } \\
\text { Project Outcomes }\end{array}$ \\
\hline & Contract & $\begin{array}{lcc}\text { Contract } \quad \text { Management, Statement } \\
\text { Management, Bidding Process List }\end{array}$ \\
\hline & Cost & $\begin{array}{l}\text { Project budget execution plan inquiry, Project } \\
\text { expense execution status inquiry, Actual Cost } \\
\text { input }\end{array}$ \\
\hline & Time & $\begin{array}{l}\text { Management Standards Process Table } \\
\text { Management, Contractor Process Table } \\
\text { Setting and Management, Performance Chart } \\
\text { Management Actual Progress Management, } \\
\text { Milestone Schedule Management Process } \\
\text { Status Inquiry, Master Schedule Inquiry, S- } \\
\text { Curve Inquiry, Primavera Tool linkage, } \\
\text { Linked log inquiry }\end{array}$ \\
\hline & Quality & $\begin{array}{l}\text { Submission management, official document } \\
\text { sending and transmission management, } \\
\text { Inspection document management, NCR } \\
\text { document management }\end{array}$ \\
\hline
\end{tabular}




\begin{tabular}{ll}
\hline Risk & Risk Register Management by Report Cycle \\
\hline & Project Document Management, Project \\
& Report Excel File Inquiry, Document \\
Document Management, & $\begin{array}{l}\text { Classification System D Document } \\
\text { Document Form Management, Docume } \\
\text { Number Management, Electronic Payment } \\
\text { Line Management }\end{array}$ \\
\hline Approval status, Scheduled / Starting Delay / \\
Complete Delay Activity, Risk Identification, \\
Recent NCR Issuance Status and My NCR \\
Inquiry, Project Notice Inquiry
\end{tabular}

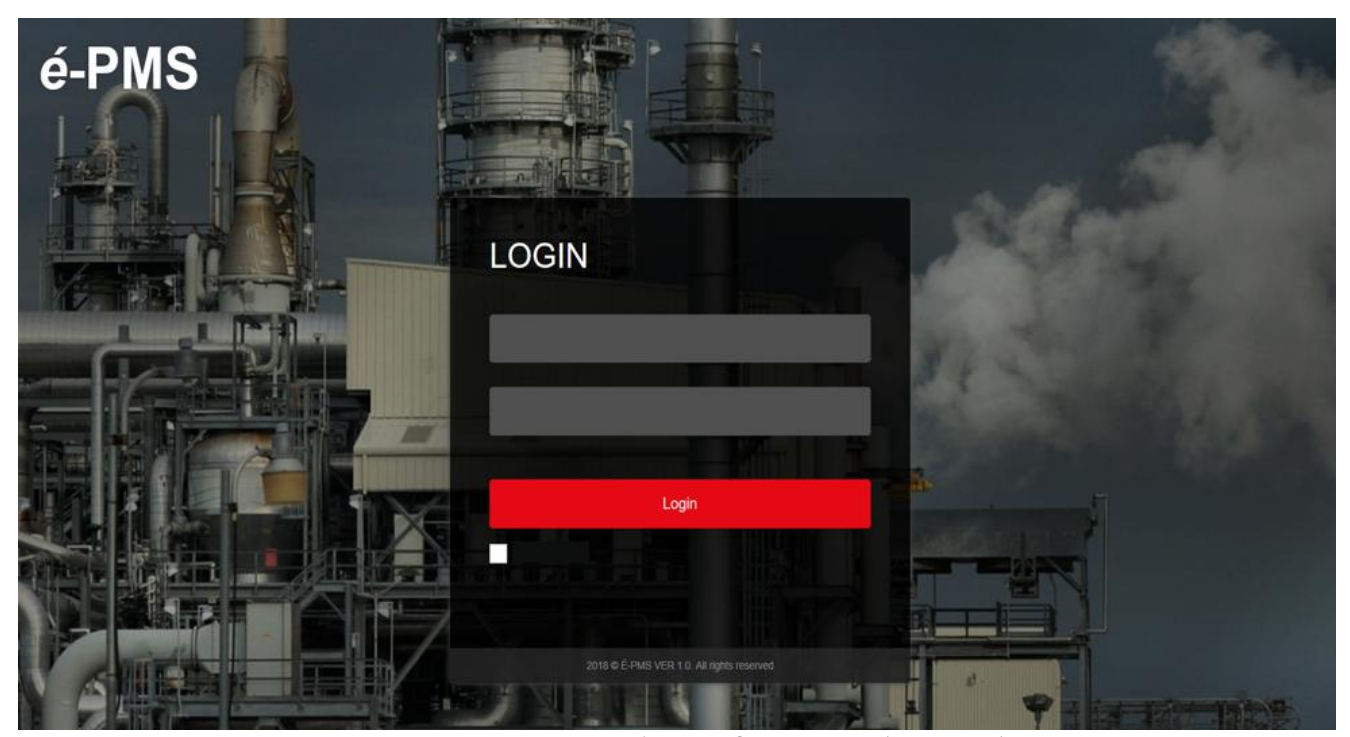

Fig. 1: Log-in window of E-PMS (Screen)

\section{DECISION-MAKING Module OF E-PMS}

\subsection{DECRIS (Detail Engineering Completion Rating Index System) Model}

The authors developed a DECRIS (Detail Engineering Completion Rating Index) system to calculate the engineering completion grade for offshore oil and gas EPC projects, using existing projects to validate their effectiveness. Because most construction schedules are tight, it is often necessary to begin construction before the design is complete. However, if the design is not finished, but the construction is started, there may be damages such as reconstruction due to the design change. Therefore, before design is complete, it is still necessary to know when it is okay to start (when damage is minimal). It is DECRIS that helps us know the point. The DECRIS methodology follows the PDRI approach, and The DECRIS model was developed in six steps:

1) DECRIS model range determination: Collect the preliminary elements from the existing literature and develop the element description 
To develop an intelligent integrated support system for engineering project (E-PMS): DECRIS and DLDs analysis

2) Data collection: Workshops were conducted with industry experts to determine which factors affect the calculation of detailed engineering completion grades and to organize the identified elements into appropriate sections and categories. Expert surveys were also used to collect data to calculate the relative importance of each element in the completion of engineering.

3) Data normalization: Determined weight factor using expert survey data, data normalization, preliminary estimation, verification process, average weight calculation of element, and interpolation.

4) Data analysis: One sample t-test was performed to complete the weight factor for each element. The weight factor of each element represents the level of factor contribution to the detailed engineering completion rating index.

5) Data application: The DECRIS model developed through the previous research stages have been validated by applying them to the 13 real projects case. Each project was evaluated using DECRIS level assessments.

6) Model verification: The score calculation results were compared with the project performance of each project using statistical analysis to confirm the level at which the model can predict project performance. A cutoff score was developed based on the model and sample project.

DECRIS is a model that predicts the increase of the construction period and construction cost based on the completeness of design. In other words, this model is developed based on the fact that the completeness of the design affects both procurement and construction. The lower the DECRIS score, the higher the completeness of the detailed design. In other words, an increase in the DECRIS score adversely affects the schedule and cost of the project. In this study, DECRIS is applied to past cases, and DECRIS acquisition scores are analyzed for each case at the main progress check point of the design. By comparing these scores with the delay level of the construction period in each case and the increase in the construction cost, a cutoff score is derived. The DECRIS cutoff scores derived from the major design progress phase were verified by regression analysis and t-test. In this study, after interviews with a practical expert with more than 15 years of plant design experience, authors have classified the design phase into 5 stages:

(1) FEED (Front-End-Engineering-Design) verification (Effective date)

(2) Equipment Procurement (30\% modeling)

(3) AFD (Approved for Design) P \& ID (60\% modeling)

(4) AFC (Approved for Construction) P \& ID (90\% modeling)

(5) Design completion.

DECRIS was applied to the stages which are as follows; FEED verification, Equipment Procurement, AFD P \& ID, AFC P \& ID to verify the cutoff score and its usefulness.

The FEED verification step, the first step in reflecting design progress, is the time to review errors in the FEED provided by the client. At this stage, authors found that cost overrun and the schedule delay highly increased when DECRIS exceeded 865 points. If the score is higher than the 865 , the cost and time are tripled than if it is lower than the score. In this study, the cutoff score was set to 865 and the usefulness was verified through regression analysis and t-test.

Equipment procurement step, the second phase of design progress, is generally the point of design review conducted in practice when modeling reaches $30 \%$. In order to 
derive the cutoff score at this stage, the DECRIS scores of each case were analyzed and compared cost and schedule delay of each project. The case B project had a $17.14 \%$ increase in construction costs and a 411-day increase when the DECRIS score was 784 . On the other hand, in the case I project, the construction cost increased by $2.84 \%$ when the DECRIS score was 674, and the construction period was delayed by 674 days. As a result, the construction period and the cost of construction increased sharply around the cutoff score 700. The authors compared increased costs and delays with higher and lower cutoff scores of 700 . The difference was analyzed to be clear.

After doing the third AFD step in a similar way, the fourth and final result is: The fourth stage of reflecting design progress, the AFC P \& ID step, is the stage of design completeness review conducted in practice when modeling reaches $90 \%$. As a result of analyzing the increased cost and the delayed period according to the DECRIS score, in case B project, when the DECRIS score was 523, the construction cost increased by $17.14 \%$ and the construction period was delayed by 411 days. On the other hand, the case I project had a DECRIS score of 243 points, a $2.84 \%$ increase in construction costs, and an 82-day delay. The high DECRIS score group which has a high average score of 456, increased construction cost was $7.52 \%$, and construction period was 229 days. On the other hand, in the case of a low DECRIS score group which has a low average score of 339 , it increased by $2.19 \%$, and 47 days. If the DECRIS score is above 380, construction costs and durations are significantly higher than below 380. (See Table 2)

Table 2: DECRIS Score of AFC P\&ID step

\begin{tabular}{|c|c|c|c|c|c|c|}
\hline \multicolumn{3}{|c|}{$\begin{array}{cc}\text { High } & \text { DECI } \\
\text { Group(Above 380) }\end{array}$} & Score & \multicolumn{2}{|c|}{$\begin{array}{cc}\text { Low } & \text { DECRIS } \\
\text { Group(Below } & 380)\end{array}$} & \multirow{2}{*}{$\begin{array}{l}\text { Score } \\
\text { Constr } \\
\text { uction } \\
\text { period(day) }\end{array}$} \\
\hline $\begin{array}{l}\text { P } \\
\text { roje } \\
\text { ct }\end{array}$ & core & $\begin{array}{l}\text { Incre } \\
\text { ased cost } \\
\text { rate }(\%)\end{array}$ & $\begin{array}{l}\text { Construc } \\
\text { tion } \\
\text { period(day) }\end{array}$ & $\begin{array}{lr}\text { roje }_{\text {ct }} & \mathrm{P} \\
\text { ctore }\end{array}$ & $\begin{array}{l}\text { Increa } \\
\text { sed cost } \\
\text { rate }(\%)\end{array}$ & \\
\hline & 82 & 6.02 & 210 & $\mathrm{I}_{43}{ }^{2}$ & 2.84 & 82 \\
\hline & 99 & 4.06 & 102 & $\mathrm{~K}_{32}{ }^{3}$ & 2.44 & 16 \\
\hline & 46 & 5.06 & 198 & $\mathrm{C}_{54}{ }^{3}$ & 2.22 & -6 \\
\hline & 49 & 8.71 & 246 & $\mathrm{~L}_{57}^{3}$ & 0.82 & 105 \\
\hline $\mathrm{F}$ & 72 & 6.09 & 305 & $\mathrm{E}_{70}{ }^{3}$ & 1.61 & 82 \\
\hline$A$ & 81 & 3.37 & 246 & $\mathrm{~J}_{77}{ }^{3}$ & 3.24 & 0 \\
\hline & 94 & 9.70 & 111 & & & \\
\hline B & 23 & 17.14 & 411 & & & \\
\hline & I & 7.5 & 229 & $\begin{array}{ll}A & 3\end{array}$ & 219 & 47 \\
\hline vg. & 56 & & & vg. 39 & & \\
\hline
\end{tabular}

Regression analysis and T-verification were performed to statistically verify the effect of each DECRIS cutoff score on the cost performance and schedule performance of 
To develop an intelligent integrated support system for engineering project (E-PMS): DECRIS and DLDs analysis

the four stages of design completion. As a result, each DECRIS cutoff score was found to have a statistically significant relationship. Each step is derived as above, and the user checks the matters step by step and grasps the influence of the process and cost by comparing the cutoff score and the derived values.

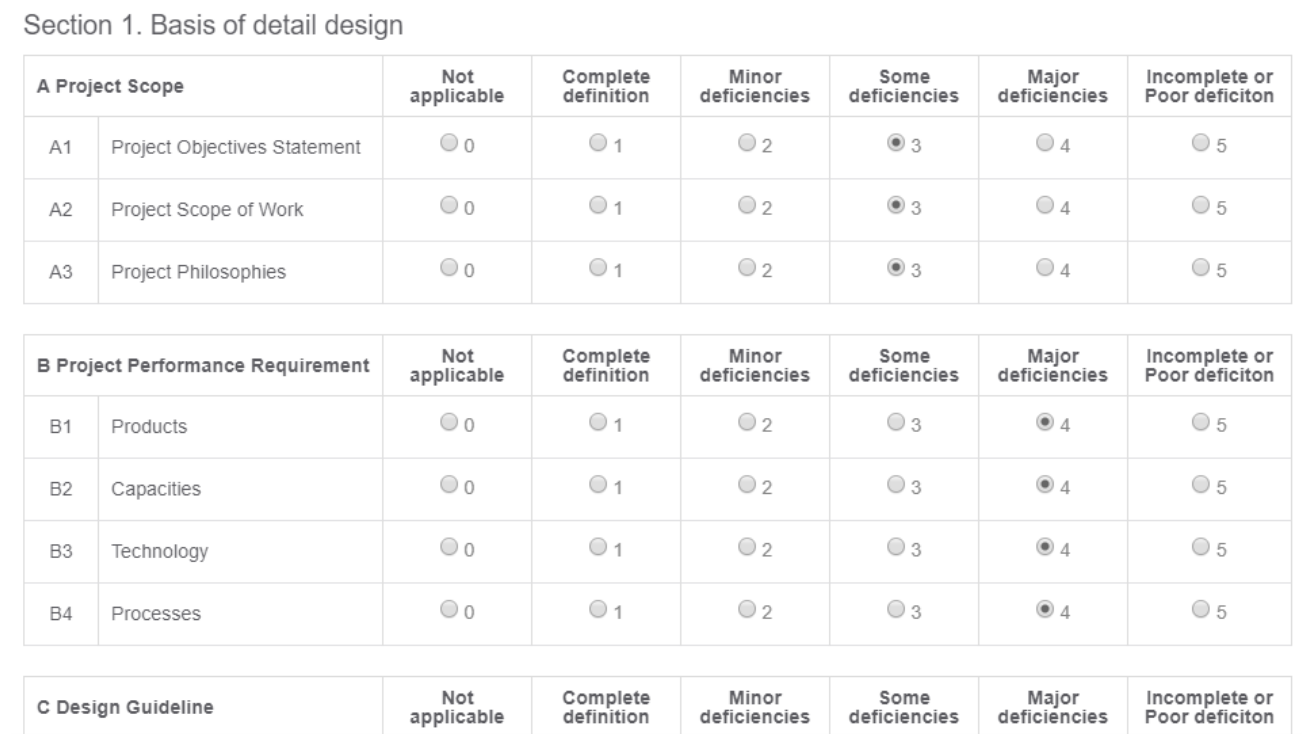

Fig. 2: DECRIS Check List: FEED verification (Effective Date) of E-PMS (Screen)

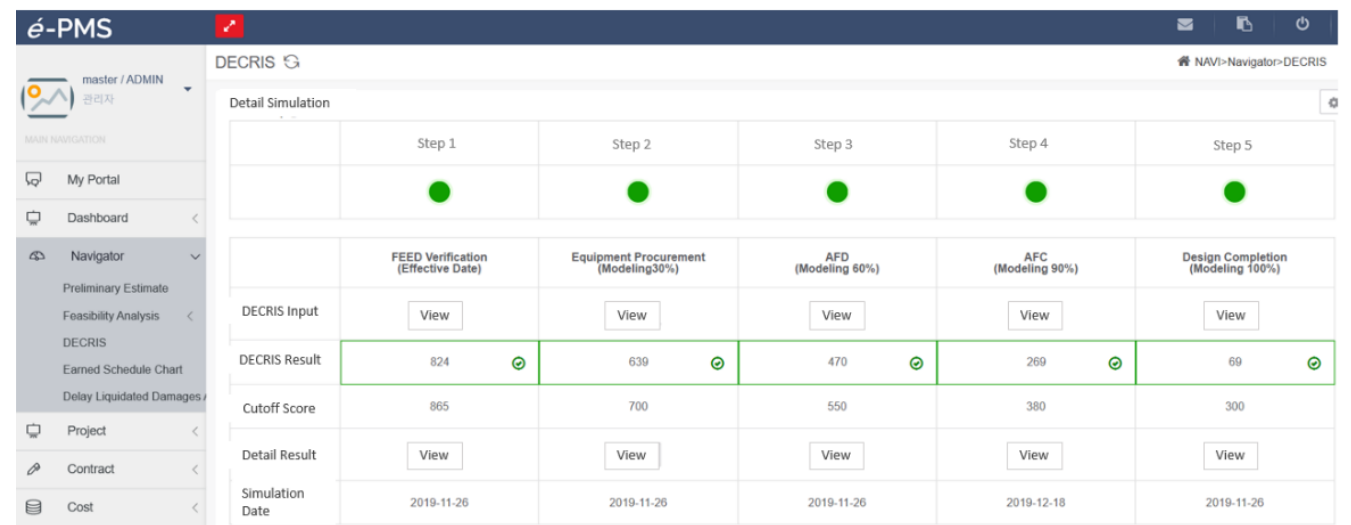

Fig. 3: DECRIS Execution Result of E-PMS (Screen)

\subsection{DLDs Analysis Model}

This study analyzes the relationship between the results of the catch-up of the construction period and the delay liquidated damages (DLDs) based on limited resources and develops a model that can support the decision on whether to perform catch-up. The validity criterion of the model is that the results of the simulation of schedule shortening do not exceed the full DLDs incurred due to no catch-up plan. The result of the schedule catch-up simulation is the cost, which is the sum of the additional budget for catch-up and the remaining DLDs. The reason for the validation criteria mentioned above is that the costs incurred for acceleration when excessive construction was performed to comply with the construction period can exceed the full DLDs. To solve this, the model was developed in three stages. First, the model was developed to predict the delay of the 
construction schedule with high accuracy. Existing EPC companies have used EVMS (Earned Value Management System) to determine their performance against plans. In other words, it analyzed whether construction was delayed. However, there is a cutoff in terms of accuracy in predicting time schedules in EVMS, which is a cost unit. To overcome this problem, the author applied the Earned Schedule (ES) algorithm, developed by Lipke in 2003 to improve the accuracy of the construction delay prediction when analyzing DLDs. Second, according to the number of critical paths in the construction stage, an appropriate option model is provided to derive shortened simulation results based on limited resources. Third, decision support information is provided through an analysis of the relationship be-tween schedule shortening results and full DLDs. In the second step, the Option Mod-el selection can be divided into $<$ Option $1>$ and $<$ Option $2>$, depending on the case of 1 and $n(\geq 2)$ critical paths. The criterion for the major classification between the two option models is the number of critical paths, and the detailed differences appear in the process of applying the shortening algorithm. In this case study, to verify the developed model, a scenario was constructed based on the data from the Vietnam Construction Project of P Company and the EPC Power Project provided by H Company (Construction Management). The scenario consisted of a 72-day delay in construction, $\Delta$ DLDs (50,000/Day), $\mathbf{\Delta}$ No Grace

Period \& Concurrent Period, and $\boldsymbol{\Delta}$ an available budget (USD 250,000). As a result, Option Model 1 accelerated 12 days in construction delay and saved USD 450,137 of its Full DLDs (USD 3,600,000). In the case of Option Model 2, the scenario saved 10 days and reduced USD 746,398 of the Full DLDs. Both Option Models meet the model validity criteria. In an EPC project, project managers (user) can predict delays in construction and check the information on activities to catch-up, whether to shorten it in order to meet the completion due date or more economical to pay the full amount of DLDs during construction. Thus, timely information can be provided to the project managers.

The DLDs Mitigation Model runs on cut-off dates. First, through ES-EVMS, the construction delay is predicted. At this time, if the construction schedule is ahead of schedule (Ahead of Schedule) or the same time (On time), the construction may be performed according to the schedule. However, if is behind schedule, move on to analysis through the DLDs Mitigation Model. Second, in the step of utilizing (analyzing) the DLDs Mitigation Model, the detailed Option Model is selected according to the number of $<$ Critical Path>. If there is one critical path, select Option Model 1; if n, select Option Model 2. Here, n means two or more. Third, after the Option Model is selected, the number of problems that may occur in the simulation process may be $\mathrm{n}$ at $\mathrm{CP}=1$. This is because, when shortened, near $\mathrm{CP}$ has the same construction period as shortened main process $(\mathrm{CP})$. Near $\mathrm{CP}$ means that the construction period is shorter than the main process, but the difference in the main process is within 30 days. During the simulation of Option Model 1, if there are multiple CPs, the simulation stops. And based on the relevant process data, through Option Model 2, it is a principle to shorten. Thus, Near CP was generated to overcome the problem. So, in Fig. 4, Option Models 1 and 2 are connected by dotted lines to indicate the possibility of the intersection. The results analyzed in this way are compared in two ways. Comparison targets include: $\triangle$ DLDs (per day) and $\Delta$ average daily reduction costs. And if the DLDs (per day) is small, it supports decision making by paying the delayed amount as much as it is delayed without performing a reduction. However, if the DLDs (per day) is large, it shorten executions to support decision making by mitigating the late compensation costs due to the delay. 
Fourth, in case of delayed compensation due to failure to shorten, support for decision making is secured by credit loss provisions. The provision for bad debts is to anticipate losses and accumulate damages in accounting accounts.

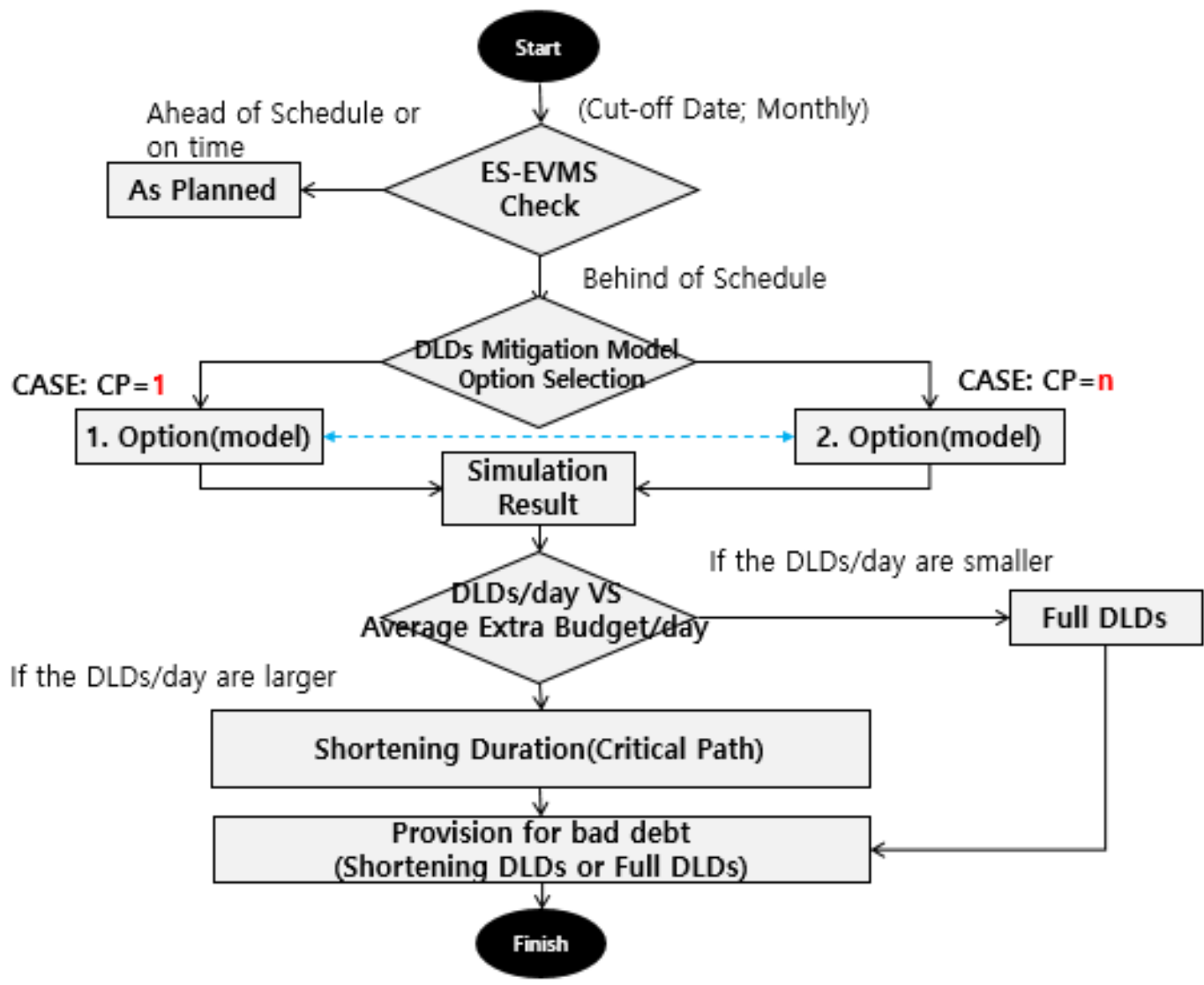

Fig. 4: DLDs Mitigation Model (Integration)

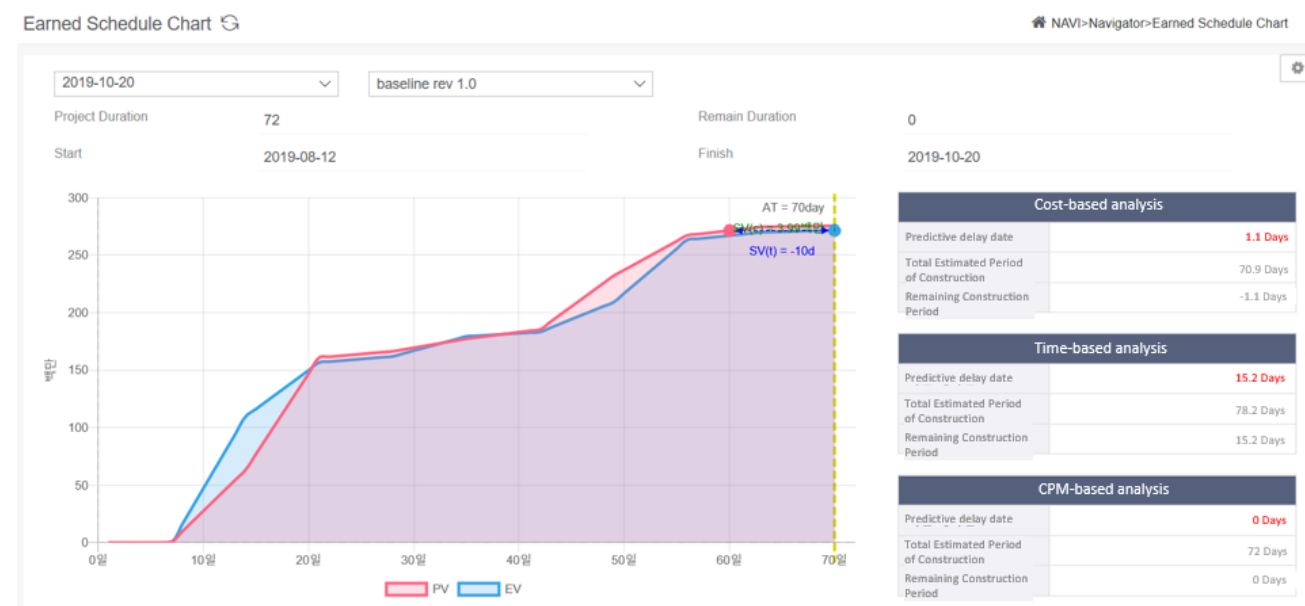

Fig. 5: Earned Schedule Chart of E-PMS (Screen) 


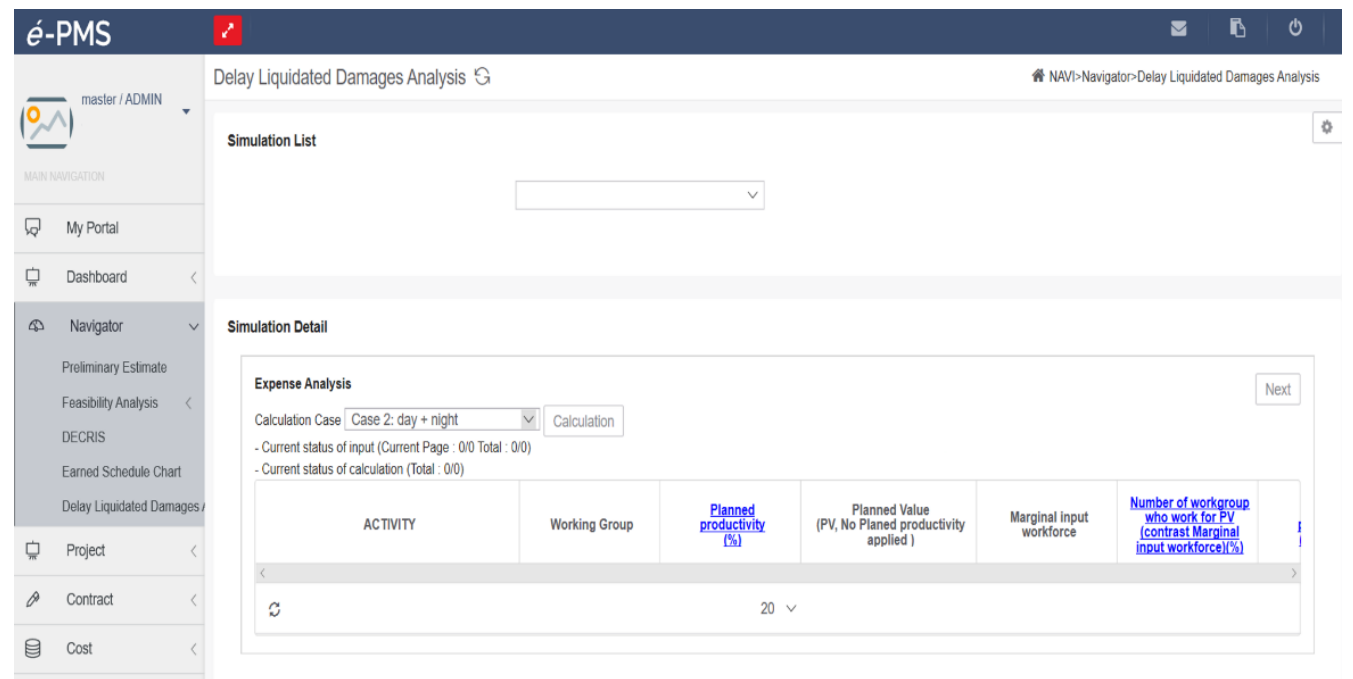

Fig. 6: Delay Liquidated Damages Analysis of E-PMS (Screen)

\section{CONCLUSIONS}

In this study, the authors developed E-PMS, an intelligent PMIS that includes decision support functions (DECRIS and DLDs Analysis). E-PMS not only manages and monitors information on all stages related to the project, but also enables optimal decision making through DECRIS and DLDs Analysis. Intelligent PMIS goes beyond the limits of what it does. With DECRIS, when the detailed design is not complete, it is possible to determine the appropriate starting point for construction based on the completeness of the design. The DECRIS model can contribute to the project success on the construction execution stage by forecasting project performance and potentially reducing the project underperformance risks. The on-time delivery within budget for offshore oil and gas EPC projects using the DECRIS model will also give a positive motivation for major oil companies who place a great deal of attention on project success. Another decision support model, DLDs Analysis (Delay Liquidated Damages, DLDs Analysis), is a model that allows additional resources to be shortened or delayed if the construction period is delayed. Decision support through DECRIS and DLDs Analysis can help EPC contractors complete successful projects by minimizing cost loss and minimizing risk.

\section{LIMITATION AND FUTURE WORKS}

Historical data from the current DECRIS model is based on the results of the EPC project of large offshore projects in Korea. It is not established that the DECRIS model can be applied to other industries or other countries with a different company organization or project characteristics. DECRIS models can be further improved and developed for various project types through further research. The DLDs Mitigation Model has a lot of initial input values and it should be easy to collect all relevant information. In fact, the field team spends a lot of time managing milestones such as Primavera 6. Given these field conditions, the limitations of the model should be enhanced automation and connectivity. The EPC contract also recommends that process control utilize commercially available tools. One of the main tools is Primavera 6, which should be 
To develop an intelligent integrated support system for engineering project (E-PMS): DECRIS and DLDs analysis

linked. In terms of usability, if the initial construction plan and the revised construction plan are mutually reflected, it will be supplemented in the above-mentioned automation.

\section{ACKNOWLEDGEMENT}

The authors acknowledge that this research was sponsored by the Korea Ministry of Trade Industry and Energy (MOTIE/KEIT) through the Technology Innovation Program funding by KEIT for (1) Artificial Intelligence Big-data (AI-BD) Platform for Engineering Decision-support Systems (grant number $=20002806$ )" and (2) Intelligent Project Management Information Systems (i-PMIS) for Engineering Projects (grant number=10077606).

\section{REFERENCES}

Jüngen, F., Kowalcyzk, W.: An intelligent interactive project management sup-port system. European Journal of Operational Research 84(1), 60-81 (1995). DOI: 10.1016/0377-2217(94)00318-7

Jaffari, A., Manivong, K.: Toward a Smart project management information system. International Journal of Project Management 16(4), 249-265 (1998). DOI: 10.1016/S0263-7863(97)00037-9

Donzelli, P.: Decision support system for software project management. IEEE Software 23(4), 67-75 (2006). DOI: 10.1109/ms.2006.90

Liu, X., Kane, G., Bambroo, M.: An intelligent early warning system for software quality improvement and project management. Journal of Systems and Software 79(11), 1552-1564 (2006). DOI: 10.1016/j.jss.2006.01.024

Labonnote, N., Skaar, Christofer., Rüther, P.: The Potential of Decision Support Systems for More Sustainable and Intelligent Constructions: a Short Overview. Procedia Manufacturing 12, 33-41 (2017). DOI: 10.1016/j.promfg.2017.08.006

Kim, C.W., Yoo, W.S., Lim, Hyunsu., Yu, I.H, C., Cho, H.H., Kang, K.I.: Early-warning performance monitoring system (EPMS) using the business information of a project. International Journal of Project Management 36(5), 730-743 (2018). DOI: 10.1016/j.ijproman.2018.03.010

Smith, P.: Project Cost Management with 5D BIM. Procedia - Social and Behavioral Sciences 226, 193-200 (2016). DOI: 10.1016/j.sbspro.2016.06.179

William.L., Richard P., Gordon S.; Sterling, G.: Deepwater Petroleum Exploration \& Production: A Nontechnical Guide. PennWell Books. 2nd ed. PenWell Corporation, USA (2011). [ISBN 978-1-59370-253-3]

Rijtema, S., de Haas, R.: Creating Sustainable Offshore Developments in the Ultra-Deep Water. In: Proceedings of the Offshore Technology Conference, pp. 4-7. Offshore Technology Conference, USA (2015). DOI: 10.4043/25873-MS

Merrow, E.W. Industrial Megaprojects: Concepts, Strategies, and Practices for Success. Wiley: Hoboken, USA (2011). [ISBN: 978-1-118-06750-5]

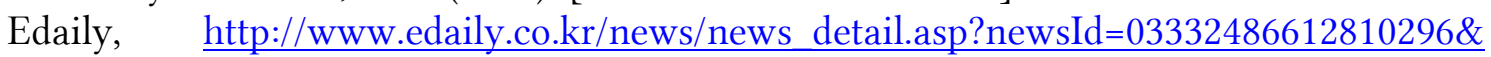
mediaCodeNo=257, last accessed 2018/03/10.

Ahn, B.: Managing the Efficiency of Foreign Engineering Contracts: A Study of a Norwegian and South Korean Project Interface. University of Stavanger, Norway (2015). DOI: $\underline{10.1016 / S 0263-7863(97) 00037-9}$ 
Tih-Ju, C., An-Pi, C., Chao-Lung, H., Jyh-Dong, L.: Intelligent Green Buildings Project Scope Definition Using Project Definition Rating Index (PDRI). Procedia Economics and Finance 18, 17-24 (2014). DOI: 10.1016/S2212-5671(14)00908-3

George, R., Bell, L.C., Back, W.E.: Critical activities in the front-end planning process. Journal of Management in Engineering 24(2), 66-74 (2008). DOI: 10.1061/(ASCE)0742-597X(2008)24:2(66)

Pheng, L.S., Chuan, Q.T.: Environmental factors and work performance of project managers in the construction industry. International Project Management, 24(1), 2437 (2006). DOI: 10.1016/j.ijproman.2005.06.001

Stenhouse, L.: The study of samples and the study of cases. British Educational Research Journal 6(1), (1980). DOI: 10.1080/0141192800060101

Thomson, S.B.: Sample size and grounded theory. Journal of Administration and Governance 5(1), 45-52 (2010). [Available at SSRN: https://ssrn.com/abstract $=3037218]$

Kline, R.B.: Principles and Practice of Structural Equation Modeling. 4th edn. Guilford Publications: New York, USA (2015). [ISBN: 978-1-4625-2334-4]

Gerbert V. D. W.: Front-End Loading in the Oil and Gas Industry. Delft University of Technology, Netherlands (2008).

Kim, M. H., Lee, E. B., Choi, H. S.: Detail Engineering Completion Rating Index System (DECRIS) for Optimal Initiation of Construction Works to Improve Contractors' Schedule-Cost Performance for Offshore Oil and Gas EPC Projects. Sustainability 10(7), 3-14 (2018). DOI: 10.3390/su10072469

Lipke, W., Kym, H.: Earned Schedule (...an extension to EVM theory). In: EVA-10 symposium, pp. 5-23, Project Management Institute (PMI), USA (2005). 